Disponível em:

http://editora.unoesc.edu.br/index.php/race

Race, Joaçaba, v. 15, n. 1, p. 201-226, jan./abr. 2016

\title{
FATORES DETERMINANTES DO DISCLOSURE DO CAPITAL HUMANO
}

\section{Determining Factors in the Disclosure of Human Capital}

\begin{abstract}
Alan Diógenes Góis
E-mail: alandgois@usp.br

Mestre em Administração e Controladoria pela Universidade Federal do Ceará; doutorando em Controladoria e Contabilidade pela Universidade de São Paulo.

Márcia Martins Mendes De Luca

E-mail: marciammdeluca@gmail.com

Doutora e Mestre em Controladoria e Contabilidade pela Universidade de São Paulo;

Professora da Universidade Federal do Ceará. Endereço para correspondência: Avenida da Universidade, 2853, Benfica, 60020181, Fortaleza, Ceará, Brasil.

José Airton Alcantara Monte Junior

E-mail: airtonalcantaramonte@gmail.com Graduando em Ciências Contábeis pela Universidade Federal do Ceará.
\end{abstract}

Artigo recebido em 11 de novembro de 2015. Aceito em 24 de novembro de 2015. 
Resumo

Nos últimos anos, percebeu-se um significativo crescimento no interesse sobre a mensuração, o gerenciamento e a evidenciação do capital intelectual. Nesse contexto, neste estudo investigaramse os fatores determinantes do disclosure do capital humano pelas empresas brasileiras listadas na BM\&FBovespa. Para tanto, foram analisados o relatório anual e/ou de sustentabilidade, a Demonstração do Valor Adicionado e dados da base Economática ${ }^{\circledR}$ de 56 empresas, referentes ao período de 2010 a 2013. A pesquisa tem natureza descritiva, com abordagem quantitativa dos dados, e utiliza-se a Regressão Linear Múltipla com dados em painel. Os resultados obtidos possibilitaram constatar que a rentabilidade e a eficiência do capital humano estão relacionadas positivamente ao disclosure do capital humano. Já o grau de intangibilidade apresentou relação inversa com o disclosure do capital humano, enquanto o tamanho, a concentração acionária e o endividamento não apresentaram relação significante. Conclui-se que, no geral, as empresas da amostra se preocupam em garantir a evidenciação do recurso estratégico capital humano em seus relatórios, apesar de ele não ser mensurado e reconhecido pela contabilidade. Cabe à gestão desenvolver estratégias que evidenciem a importância dos colaboradores, assim como implementar políticas de investimento na criação e retenção de talentos, pois esse recurso favorece a vantagem competitiva, de acordo com os preceitos da Visão Baseada em Recursos. Palavras-chave: Capital intelectual. Capital humano. Disclosure. Visão baseada em recursos.

\title{
Determining Factors in the Disclosure of Human Capital
}

\begin{abstract}
In the past few years, a significant increase in interest in measurement, managing and evidencing of intellectual capital has been observed. In this context, the study has investigated the determining factors in the disclosure of human capital by Brazilian companies listed on the BM\&FBovespa. In order to do so, there was an analysis of the annual report and/or the sustainability report, the statement of added value and data from the Economática ${ }^{\circledR}$ of 56 companies referring the 2010-to-2013 period. The research is of descriptive nature, with a quantitative approach to data, and employs the Multiple Linear Regression with data on panel. The obtained results made it possible to observe that profitability and human capital efficiency are positively related to the disclosure of human capital. On the other hand, the degree of intangibility has presented an inverted relation with the disclosure of human capital, while size, share concentration and debt have not presented significant relation. It has been concluded that, in general, the sample companies are concerned with ensuring the evidencing of the human capital strategic resource in their reports, although it is not measured and recognized by the financial accounting. It is the managers' job to develop strategies that will evidence the importance of collaborators and implement investment policies towards the creation and
\end{abstract}


keeping of talent because this resource leads to a competitive edge, according to the precepts of the Resource-Based View.

Keywords: Intellectual capital. Human capital. Disclosure. Resource-Based View.

\section{INTRODUÇÃO}

Nos últimos anos, percebeu-se um significativo crescimento no interesse sobre a mensuração, o gerenciamento e a evidenciação do capital intelectual (AX; MARTON, 2008). Por sua vez, de acordo com Yi e Davey (2010), o capital intelectual não possui um conceito definido, sendo considerado um ativo intangível ou recurso de conhecimento que pode criar valor para a empresa, além de ajudar a alcançar e a manter a competitividade.

Nessa perspectiva, Guthrie, Petty e Ricceri (2006) asseveram que para muitas empresas o capital intelectual representa uma expressiva parcela do seu valor. Ressalte-se que, apesar de sua importância, o capital intelectual não é reconhecido nos demonstrativos financeiros, pois sua concepção não atende à definição de ativo segundo as normas contábeis (GUTHRIE; PETTY; RICCERI, 2006; SINGH; KANSAL, 2011; SONNIER, 2008).

Destarte, as empresas passaram a evidenciar as informações relacionadas ao capital intelectual, muitas vezes em razão das exigências dos stakeholders, mas também por reconhecer o seu valor e a sua capacidade de geração de desempenho superior (VERGAUWEN; ALEM, 2005).

Como se trata de uma evidenciação voluntária, Eccles e Mavrinac (1995) afirmam que essa decisão pode impactar positivamente a credibilidade da gestão, o entendimento dos analistas e a compreensão dos investidores quanto a desempenhos inferiores.

Para tanto, White, Lee e Tower (2007) alertam que as empresas precisam dar atenção à divulgação sobre o conhecimento dos empregados, a relação com clientes, a visão estratégica e a propriedade intelectual, considerados fatores-chave para melhor desempenho e criação de valor. Segundo Mouritsen, Larsen e Bukh (2005), esses assuntos são descritos nos relatórios anuais e definem o capital intelectual, que se divide em três dimensões: capital humano, relação interna e relação externa.

O capital humano é reconhecido como o principal fator da criação do capital intelectual, e sua característica distintiva é que ele pode simplesmente desaparecer com a saída de empregados, sendo, ainda, fonte de inovação e renovação estratégica (BONTIS, 1999). 
O capital humano tem recebido atenção, ainda, por gerar benefícios significativos, que podem ser obtidos por meio da melhor informação sobre os recursos humanos da organização (SACKMAN; FLAMHOLTZ; BULLEN, 1989). Além disso, a atenção dispensada ao capital humano transforma a concepção de que os empregados não são custos, mas, sim, investimentos, demonstrando a boa postura da empresa quanto aos seus recursos humanos e contribuindo, assim, para o recrutamento e, em especial, para a retenção de talentos (BOUDREAU; RAMSTAD, 1997; OLSSON, 1999; PULIC, 2004; VERGAUWEN; ALEM, 2005).

Segundo Barney (1991) e Grant (1991), o capital humano é reconhecido pela Visão Baseada em Recursos como um recurso crítico, pois a empresa apenas o possui enquanto o empregado faz parte do quadro de pessoal; no momento da sua saída da empresa, este leva consigo todo o conhecimento (SHIH; CHANG; LIN, 2010). Com base nessa teoria, Sonnier (2008) define capital humano como conhecimento, competência, expertise, educação e treinamento, experiência e lealdade com a empresa, incluindo, também, a criatividade, o know-how, a satisfação e a capacidade de trabalho em equipe e de aprendizagem.

A literatura aponta diversos fatores que influenciam a divulgação do capital intelectual ou do capital humano pelas empresas, entre os quais, neste estudo, são investigados os seguintes: o tamanho, a concentração acionária, o grau de intangibilidade, o desempenho, o endividamento e a eficiência do capital humano (CHEN; CHENG; HWANG, 2005; CLARKE; SENG; WHITING, 2011; FELÍCIO; COUTO; CAIADO, 2014; FERREIRA, 2008; GUTHRIE; PETTY; RICCERI, 2006; MAÇAMBANNI et al., 2012; SÁENZ, 2005; WHITING; WOODCOCK, 2011).

Com base no exposto, o estudo levanta o seguinte questionamento: quais fatores determinam o disclosure do capital humano pelas empresas brasileiras listadas na BM\&FBovespa?

Desse modo, objetivou-se a presente pesquisa, investigar os fatores determinantes do disclosure do capital humano pelas empresas brasileiras listadas na BM\&FBovespa. Adicionalmente, verificou-se se há associação entre o disclosure do capital humano e os setores econômicos das empresas da amostra.

Na literatura há inúmeras obras abordando o disclosure do capital intelectual em diversos países (APRIL; BOSMA; DEGLON, 2003; BONTIS, 2003; BOZZOLAN; FAVOTTO; RICCERI, 2003; PETTY; GUTHRIE, 2000). Entretanto, quanto ao disclosure do capital humano (considerado uma dimensão do capital intelectual), verifica-se que são raras as pesquisas. Outro dado importante é que no presente estudo se faz uma análise temporal do disclosure do capital humano e procura-se definir fato- 
res que influenciam a sua divulgação pelas empresas brasileiras, pois muitas pesquisas atentam somente para os aspectos relacionados ao desempenho econômico-financeiro.

\section{REFERENCIAL TEÓRICO}

A Visão Baseada em Recursos sugere que a vantagem competitiva resulta da interação entre os recursos internos que posicionam determinada empresa adiante de seus concorrentes (PAIVA; BARBOSA; GONÇALVES, 2008). Segundo Barney (1991), os recursos de uma organização podem ser considerados ativos, capacidades, processos organizacionais, recursos financeiros, físicos e humanos, informações e conhecimentos, os quais a empresa controla e por meio dos quais ela recebe auxílio para formular e pôr em prática estratégias eficazes (BARNEY, 1991; TONDOLO; BITENCOURT, 2008).

Para poder produzir vantagem competitiva, os recursos devem possuir certas características, como o valor, a raridade e a imitabilidade, sendo estas mais presentes em recursos intangíveis (BARNEY, 1991; BINDER, 2009; BRITO; VASCONCELOS, 2004). Considerado recurso intangível, o capital intelectual, segundo a Organisation for Economic Co-operation and Development OECD (1999), é o valor econômico de duas categorias de ativos intangíveis das organizações, ou seja, o capital organizacional (estrutural) e o capital humano. O capital organizacional refere-se aos sistemas, network e cadeia de suprimentos. Já o capital humano diz respeito aos recursos humanos.

Para Brooking (1997), o capital intelectual é a consequência da utilização eficiente dos ativos intangíveis resultantes das mudanças nas áreas da empresa relacionadas ao conhecimento, gerando benefícios que podem ser usados para criar uma vantagem diferencial. O capital intelectual pode se dividir em quatro categorias: ativos de mercado, ativos humanos, ativos de propriedade intelectual e ativos de infraestrutura (BROOKING, 1997).

Por sua vez, Edvinsson e Malone (1997) conceituam que o capital intelectual representa os fatores dinâmicos ocultos em uma organização, podendo ser dividido em capital estrutural, capital de clientes e capital humano.

Já Bozzolan, Favotto e Ricceri (2003) definem capital intelectual como o conjunto dos ativos intangíveis da organização que não podem ser mensurados pela contabilidade. Esses ativos são divididos entre três dimensões: estrutura interna, estrutura externa e capital humano. O Quadro 1 apresenta os principais ativos que compõem as três dimensões do capital intelectual, de acordo com os autores citados. 
Quadro 1 - Composição do capital intelectual

\begin{tabular}{|l|l|}
\hline Dimensão & Composição \\
\hline $\begin{array}{l}\text { Estrutura } \\
\text { interna }\end{array}$ & $\begin{array}{l}\text { Inclui a propriedade intelectual e os ativos de infraestrutura. A propriedade intelectual } \\
\text { consiste em ativos protegidos por lei, como as patentes, os direitos autorais e as mar- } \\
\text { cas registradas. Já os ativos de infraestrutura consistem em elementos que podem ser } \\
\text { adquiridos ou criados, como a cultura corporativa, o processo de gestão, o sistema de } \\
\text { informação, o sistema de networking e os projetos de pesquisa. }\end{array}$ \\
\hline $\begin{array}{l}\text { Estrutura } \\
\text { externa }\end{array}$ & $\begin{array}{l}\text { Refere-se às relações que a empresa mantém com stakeholders externos. Inclui marcas, } \\
\text { clientes, fidelidade com clientes, canais de distribuição, alianças, pesquisas em conjun- } \\
\text { to, contatos financeiros e acordos de licenciamento e franchising. }\end{array}$ \\
\hline $\begin{array}{l}\text { Capital } \\
\text { humano }\end{array}$ & $\begin{array}{l}\text { Conção, o conhecimento e a competência relacionados ao trabalho, além da idade e da } \\
\text { rotatividade. }\end{array}$ \\
\hline
\end{tabular}

Fonte: adaptado de Bozzolan, Favotto e Ricceri (2003).

Goh e Lim (2004) observam que ao redor do mundo houve significativo crescimento no reconhecimento e na utilização do capital intelectual, o que ajuda as empresas a serem mais eficientes, efetivas, produtivas e inovadoras. Todavia, as empresas devem dar mais atenção ao capital humano, já que ele é o principal fator da criação do capital intelectual (BONTIS, 1999).

Foco deste estudo, o capital humano, segundo Edvinsson e Malone (1997), está relacionado ao conhecimento, à expertise, ao poder de inovação e à habilidade dos empregados, além de aos valores, à cultura e à filosofia da entidade. Desse modo, o capital humano está associado aos benefícios que podem ser proporcionados pelos empregados à organização. Nessa mesma linha, Carvalho e Souza (1999, p. 2) caracterizam o capital humano como “[...] capacidade, conhecimento, habilidade, criatividade e experiências individuais dos empregados e gerente transformando em produtos e serviços que são o motivo pelo qual os clientes procuram a empresa e não o concorrente.”

O Quadro 2 apresenta as principais definições de ativo humano e capital humano na literatura.

Quadro 2 - Definições de ativo humano e capital humano

\begin{tabular}{|l|l|l|}
\hline Autor & Dimensão & Definição \\
\hline $\begin{array}{l}\text { Brooking } \\
(1997)\end{array}$ & Ativo humano & $\begin{array}{l}\text { Compreende as competências, habilidades e expertise, habilidade } \\
\text { de resolução de problemas e estilo de liderança dos empregados. }\end{array}$ \\
\hline $\begin{array}{l}\text { Stewart } \\
(1997)\end{array}$ & $\begin{array}{l}\text { Capital hu- } \\
\text { mano }\end{array}$ & $\begin{array}{l}\text { Está relacionado aos empregados, considerados o ativo mais impor- } \\
\text { tante em uma empresa. }\end{array}$ \\
\hline Roos (1998) & $\begin{array}{l}\text { Capital hu- } \\
\text { mano }\end{array}$ & $\begin{array}{l}\text { Refere-se à competência, atitude e agilidade intelectual dos empre- } \\
\text { gados. }\end{array}$ \\
\hline $\begin{array}{l}\text { Bontis } \\
(1999)\end{array}$ & $\begin{array}{l}\text { Capital hu- } \\
\text { mano }\end{array}$ & É considerado o nível de conhecimento de cada empregado. \\
\hline
\end{tabular}

Fonte: os autores. 
Destarte, o capital humano diz respeito a todo o conhecimento e à habilidade que um empregado detém e utiliza em prol da empresa, sendo de responsabilidade desta procurar retê-lo e impulsionar o seu talento.

Mesmo sendo de grande importância para as organizações (BONTIS, 1999), o capital humano, assim como as outras dimensões do capital intelectual, não é registrado pela contabilidade em razão da dificuldade de mensuração, em especial, pois inexistem técnicas capazes de quantificar confiavelmente esses recursos intangíveis (GUTHRIE; PETTY; RICCERI, 2006; SINGH; KANSAL, 2011; SONNIER, 2008). Assim, tem-se no disclosure, em relatórios anuais (ou similares), um meio de se perceber o desenvolvimento do capital humano (SVEIBY, 1997).

O disclosure pode ser caracterizado em duas dimensões: voluntária e obrigatória. Segundo Beuren, Hein e Boff (2011), a evidenciação feita pelas empresas é, em grande parte, obrigatória por lei, que determina o que deve ser feito e publicado em termos de demonstrações contábeis, para que, por meio delas, os usuários da informação contábil possam tomar decisões seguras. Já a evidenciação voluntária ocorre quando as empresas divulgam informações que vão além daquelas exigidas por leis e normas (PIACENTINI, 2004).

Entre os diversos documentos por meio dos quais as empresas levam ao público informações sobre suas ações destaca-se o relatório anual, um dos mais importantes, já que é o principal meio de comunicação com os stakeholders sobre as atividades e intenções da empresa (HOLLAND; FOO, 2003).

Diversos estudos discorrem sobre a demanda dos usuários dos relatórios anuais por informações confiáveis relacionadas a determinados assuntos, como o capital humano, que é fonte capaz de criar valor e melhorar o desempenho das empresas (ABEYSEKERA; GUTHRIE, 2004; BEATTIE, 2000; MAINES et al., 2002).

Destarte, o disclosure do capital humano se enquadra como informação voluntária e atualmente presente nos relatórios de diversas organizações, em razão da prática de mais transparência com o intuito de atrair mais investidores (PIACENTINI, 2004). Destaque-se, ainda, que uma melhor gestão busca a valorização de seus colaboradores, pois estes podem trazer benefícios competitivos para a empresa, inclusive superando aqueles advindos de seus ativos tangíveis.

Nesse contexto, cada dia mais as empresas estão adotando um conjunto de políticas que melhoram o desempenho e o bem-estar dos empregados, entre as quais se destacam melhores salários e benefícios, clima de trabalho estimulante, perspectivas de desenvolvimento na carreira, possibilidade de desenvolvimento e realização 
profissional (TOLFO; PICCININI, 2001). A adoção dessas práticas pode trazer vantagem competitiva para as empresas, em decorrência do papel que o capital humano desempenha nas organizações.

Autores como Chen, Cheng e Hwang (2005), Clarke, Seng e Whiting (2011), Felício, Couto e Caiado (2014), Ferreira (2008) e Sáenz (2005) verificaram a relação entre o capital intelectual, assim como o capital humano, e diversos fatores ou características organizacionais.

Chen, Cheng e Hwang (2005) investigaram a relação entre o capital intelectual e o valor de mercado e o desempenho financeiro das empresas taiwanesas. Os resultados demonstraram que o capital intelectual impacta positivamente o valor de mercado e o desempenho financeiro, podendo ser um indicador de desempenho financeiro futuro.

Sáenz (2005) investigou a relação entre o capital humano e o market-to-book (grau de intangibilidade), bem como entre o capital humano e o desempenho financeiro nos bancos da Espanha. Os resultados demonstraram uma relação positiva entre o capital humano e o market-to-book, sem, entretanto, identificar qualquer relação entre o capital humano e o desempenho financeiro.

Guthrie, Petty e Ricceri (2006) investigaram se o tamanho, o setor de atividade e os efeitos do tempo influenciam o disclosure do capital intelectual nas empresas da Austrália e de Hong Kong. Os resultados demonstraram que o nível de disclosure está positivamente relacionado ao tamanho da empresa, e que, no entanto, o setor e o efeito do tempo não se revelaram significantes.

Ferreira (2008) investigou a identificação das tendências e dos fatores explicativos do nível de divulgação voluntária de informações sobre o capital intelectual em Portugal. Os resultados indicaram que os fatores explicativos da divulgação em Portugal são o tamanho e a empresa de auditoria. Contrariamente ao que seria de se esperar, a concentração acionária, o endividamento, a rentabilidade, o nível de divulgação do capital intelectual e a indústria não se revelaram fatores explicativos.

Clarke, Seng e Whiting (2011) investigaram o efeito do capital intelectual sobre o desempenho de empresas australianas. Os resultados apontaram que há uma relação direta entre o capital intelectual, mensurado pelo Value Added Intellectual Capital, e o desempenho das empresas australianas de capital aberto.

Whiting e Woodcock (2011) investigaram a presença de divulgação voluntária de capital intelectual nos relatórios das empresas australianas e a influência das características da empresa (tipo de indústria, concentração da propriedade, idade, alavancagem e tipo de auditor) nessa divulgação. Os resultados evidenciaram que as em- 
presas que atuam em setores de alta base tecnológica ou de conhecimento intensivo, assim como aquelas auditadas pelas Big Four, promovem mais divulgação voluntária de capital intelectual. Enquanto isso, a concentração acionária, o endividamento e a idade não se mostraram significantes nesse aspecto.

Maçambanni et al. (2012) investigaram a associação entre o nível de disclosure dos elementos componentes do capital intelectual e as características das empresas listadas no Índice BM\&FBovespa. Os resultados revelaram que o nível de disclosure do capital intelectual possui associação com o tamanho e o nível de rentabilidade das empresas, enquanto a variável governança corporativa não apresenta associação com o nível de disclosure.

Felício, Couto e Caiado (2014) investigaram o capital humano e o capital social de gestores e a influência desses atributos sobre o desempenho das pequenas e médias empresas portuguesas. Os resultados mostraram que o desempenho organizacional é fortemente influenciado pelo capital humano.

Com base na revisão da literatura (CHEN; CHENG; HWANG, 2005; CLARKE; SENG; WHITING, 2011; FELÍCIO; COUTO; CAIADO, 2014; FERREIRA, 2008; GUTHRIE; PETTY; RICCERI, 2006; MAÇAMBANNI et al., 2012; SÁENZ, 2005; WHITING; WOODCOCK, 2011), foram identificados alguns fatores intrínsecos das organizações que impactam o nível de divulgação voluntária, sob o enfoque do capital humano. A partir desses fatores, foram delineadas seis hipóteses, a saber:

$\mathrm{H}_{1}-\mathrm{O}$ tamanho da empresa está relacionado positivamente com o disclosure do capital humano.

O tamanho da empresa está associado ao grau de evidenciação do capital humano nos relatórios anuais, pois é de se esperar que quanto maior é a empresa, mais elevado é o nível de evidenciação, já que se procura reduzir os custos políticos envolvendo determinados grupos de stakeholders (WHITE; LEE; TOWER, 2007). Além do que, as empresas maiores chamam a atenção de grandes investidores, razão pela qual a evidenciação pode trazer benefícios (HOSSAIN, 2008). E, segundo Oliveira, Rodrigues e Craig (2010), as empresas de grande porte são mais propensas a destinar mais recursos financeiros, organizacionais e humanos para produzir a informação.

$\mathrm{H}_{2}$ - A rentabilidade está relacionada positivamente com o disclosure do capital humano. 
Segundo Akerlof (1970) e Meek, Roberts e Gray (1995), as empresas mais rentáveis tendem a divulgar mais informações, como forma de se diferenciar das menos rentáveis, reduzindo o risco de seleção adversa e podendo gerar diversos benefícios. Domench e Dallo (2001) observam que os gestores tendem a divulgar um volume maior de informações quando a empresa se encontra em situação financeira positiva. Dessa forma, as empresas mais rentáveis tornam-se mais visíveis no mercado, atraindo investidores que, por sua vez, buscam maior volume de informações que os auxiliem nas decisões acerca da perpetuidade dos retornos esperados.

$\mathrm{H}_{3}-\mathrm{O}$ endividamento está relacionado positivamente com o disclosure do capital humano.

As empresas com maior grau de endividamento tendem a praticar a divulgação em nível mais elevado, em razão da necessidade de fornecer mais informações a seus credores, já que estes tendem a monitorar fortemente a gestão (ALBERS; GÜNTHER, 2010; LANZANA, 2004; REVERTE, 2009). Para Whiting e Woodcock (2011), as organizações com elevado grau de endividamento são propensas a divulgar informações sobre o capital intelectual e, por sua vez, sobre o capital humano, com o intuito de reduzir os custos de agência.

$\mathrm{H}_{4}$ - O grau de intangibilidade está relacionado positivamente com o disclosure do capital humano.

O capital humano é um recurso intangível das organizações (PETTY; GUTHRIE, 2000), e, segundo Sveiby (1998), as empresas tendem a divulgar informações sobre seus intangíveis, pois as utilizam para conhecimento, monitoramento e para fundamentar decisões corretivas, além do que o disclosure é fonte de transparência perante os seus stakeholders. Desse modo, quanto mais “intangível” for uma empresa, maior é a sua necessidade de evidenciar informações sobre o capital humano.

$\mathrm{H}_{5}$ - A concentração acionária está relacionada negativamente com o disclosure do capital humano.

Whiting e Woodcock (2011) comentam que a concentração acionária produz efeitos negativos no disclosure do capital intelectual, em decorrência da existência de assimetria informacional. Nesse contexto, a concentração das ações em uma única pessoa 
faz com que determinadas informações sejam privadas, o que seria diferente caso o capital fosse disperso, pois haveria mais pressão dos acionistas a fim de reduzir a assimetria informacional; logo, haveria mais divulgação do capital humano (RAFFOURNIER, 1995).

$\mathrm{H}_{6}$ - A eficiência do capital humano está relacionada positivamente com o disclosure do capital humano.

Pulic (1998) mostra que por meio do valor adicionado é possível chegar ao valor do capital intelectual, o qual se divide em três categorias (eficiência do capital humano, eficiência do capital estrutural e eficiência do capital empregado). O valor adicionado representa a riqueza criada pelos stakeholders de uma empresa (CUNHA; RIBEIRO; SANTOS, 2005), incluindo os empregados, e é calculado pela diferença entre a receita de vendas líquidas e os bens e serviços comprados ou o custo dos produtos/ serviços vendidos (RIAHI-BELKAOUI, 2003). A eficiência do capital humano diz respeito aos empregados, sendo representada pelos salários e benefícios (PULIC, 1998). Segundo Clarke, Seng e Whiting (2011), maiores salários e benefícios concedidos a uma força de trabalho com mais competência devem agregar mais valor para a empresa do que um quadro de pessoal com salários e benefícios mais baixos. Assim, as empresas com mais eficiência do capital humano tendem a divulgar mais informações sobre o capital humano, já que o disclosure demonstra a política da empresa voltada para seus empregados, atraindo talentos e gerando benefícios futuros (BHASIN; SHAIKH, 2011).

A partir dessas hipóteses, no presente estudo propõe-se, considerando uma análise temporal, testar a existência de evidências estatísticas que definam os fatores que influenciam o disclosure do capital humano pelas empresas brasileiras listadas na BM\&FBovespa.

\section{METODOLOGIA}

O presente estudo se enquadra como pesquisa descritiva, pois se identificam e se obtêm informações sobre as características de um problema específico (COLLIS; HUSSEY, 2005). Quanto à abordagem, a pesquisa é considerada quantitativa, porque se testam hipóteses com base na medição numérica, utilizando-se, também, a análise estatística para estabelecer padrões de comportamento (SAMPIERI; COLLADO; LÚCIO, 2013). Quanto aos procedimentos, é documental, já que utiliza materiais não editados (MARTINS; THEÓPHILO, 2009).

A população da pesquisa compreende todas as empresas listadas na BM\&FBovespa. Por sua vez, a amostra reúne 56 empresas que divulgaram relatórios anuais 
e/ou de sustentabilidade referentes aos exercícios de 2010, 2011, 2012 e 2013, nos seus websites institucionais no período da coleta (outubro e novembro de 2014), totalizando 224 observações. Inicialmente, o estudo contemplaria a análise dos relatórios anuais e/ou de sustentabilidade dos cinco anos mais recentes à época da coleta dos dados, porém, como tais relatórios são de caráter voluntário, esse fator limitou o período de análise a quatro anos para se obter melhor aproveitamento do número de observações.

Para o disclosure do capital humano, foi aplicada a análise de conteúdo, que, segundo Bardin (2009), compreende o conteúdo, eventualmente sua forma e a sua distribuição. Os relatórios foram analisados com base no índice adaptado de Maçambanni et al. (2012), conforme mostra o Quadro 3.

Quadro 3 - Índice do disclosure do capital humano

\begin{tabular}{|l|l|}
\hline \multicolumn{2}{|l|}{ Questões do disclosure do capital humano } \\
\hline 1 & A empresa considera os colaboradores como ativo/recurso/capital? \\
\hline 2 & $\begin{array}{l}\text { A empresa incentiva a participação dos colaboradores, o trabalho em equipe ou o desenvolvi- } \\
\text { mento de novas ideias por parte dos colaboradores? }\end{array}$ \\
\hline 3 & A empresa informa o montante investido na educação dos colaboradores? \\
\hline 4 & $\begin{array}{l}\text { A empresa informa o montante investido no treinamento/desenvolvimento/capacitação dos } \\
\text { colaboradores? }\end{array}$ \\
\hline 5 & A empresa procura reter ou captar talentos? \\
\hline 6 & A empresa demonstra a qualificação profissional e o nível de escolaridade dos colaboradores? \\
\hline 7 & A empresa divulga o índice de rotatividade dos colaboradores? \\
\hline 8 & $\begin{array}{l}\text { A empresa evidencia os benefícios que não são obrigatórios por lei concedidos aos colaborado- } \\
\text { res? }\end{array}$ \\
\hline 9 & A empresa faz pesquisa de clima organizacional ou de satisfação dos colaboradores? \\
\hline 10 & A empresa menciona questões como experiências e competências relacionadas ao trabalho? \\
\hline 11 & A empresa incentiva o espírito empreendedor ou de liderança em seus colaboradores? \\
\hline 12 & A empresa menciona questões como eficiência, eficácia e confiança relacionadas ao trabalho? \\
\hline
\end{tabular}

Fonte: adaptado de Maçambanni et al. (2012).

O índice de disclosure do capital humano de cada empresa foi obtido da seguinte forma: atribuiu-se o valor " 1 ” quando a empresa respondeu positivamente a cada pergunta, e o valor “ 0 ”, no caso contrário. O somatório dos pontos alcançados foi dividido por 12, que representa o número máximo de pontos do índice. Logo, se uma empresa chegar a 12 pontos, o índice de disclosure do capital humano alcança 100\%.

As variáveis consideradas fatores determinantes do disclosure do capital humano foram obtidas na base de dados Economática ${ }^{\circledR}$ e na Demonstração do Valor Adicionado referentes aos exercícios de 2010, 2011, 2012 e 2013.

Para testar as hipóteses do estudo, aplicou-se a Regressão Linear Múltipla com dados em painel, em que há a combinação do componente transversal, repre- 
sentado pelas 56 empresas da amostra, com o componente temporal, já que o período de análise compreende quatro anos, totalizando 224 observações. Nesta pesquisa, os dados foram organizados em painéis balanceados, já que cada indivíduo está presente em todo o período analisado. Destarte, foi desenvolvido um modelo matemático, em que o disclosure do capital humano é a variável dependente, e os fatores determinantes são as variáveis independentes, conforme mostrado na Equação 1.

$\mathrm{DCH}_{\mathrm{it}}=\beta_{0}+\beta_{1} \mathrm{TAM}_{\mathrm{it}}+\beta_{2} \mathrm{ROE}_{\mathrm{it}}+\beta_{3} \mathrm{END}_{\mathrm{it}}+\beta_{4} \mathrm{GRI}_{\mathrm{it}}+\beta_{5} \mathrm{CAC}_{\mathrm{it}}+\beta_{6} \mathrm{ECH}_{\mathrm{it}}+\varepsilon_{\mathrm{it}}$

O Quadro 4 apresenta as variáveis utilizadas para se testarem as hipóteses do estudo, a sua definição, bem como a sua operacionalização.

Quadro 4 - Definição e operacionalização das variáveis

\begin{tabular}{|l|l|l|}
\hline Variável & Descrição & Operacionalização \\
\hline DCH & $\begin{array}{l}\text { Disclosure do Capital Hu- } \\
\text { mano }\end{array}$ & $\begin{array}{l}\text { Raiz quadrada do índice adaptado do estudo de Maçam- } \\
\text { banni et al. (2012) }\end{array}$ \\
\hline TAM & Tamanho & Logaritmo do Ativo Total \\
\hline ROE & $\begin{array}{l}\text { Rentabilidade: Return On } \\
\text { Equity }\end{array}$ & Razão entre o Lucro Líquido e o Patrimônio Líquido \\
\hline END & Endividamento & Razão entre o Passivo Exigível e o Ativo Total \\
\hline GRI & Grau de Intangibilidade & Razão entre o Valor de Mercado e o Patrimônio Líquido \\
\hline CAC & Concentração Acionária & Proporção das ações pertencentes ao maior acionista \\
\hline ECH & $\begin{array}{l}\text { Eficiência do Capital Hu- } \\
\text { mano }\end{array}$ & $\begin{array}{l}\text { Razão entre o valor adicionado distribuído para empre- } \\
\text { gados e o valor adicionado total }\end{array}$ \\
\hline
\end{tabular}

Fonte: os autores.

Realizaram-se os testes Lagrange Multiplier (LM), de Breusch-Pagan e de Hausman, para se identificar a melhor abordagem para a representação dos dados: pooled, painel de efeitos fixos ou efeitos aleatórios. O tratamento dos dados em painel foi realizado com o auxílio do aplicativo Stata, versão 13.

\section{ANÁLISE DOS RESULTADOS}

Inicialmente, realizou-se uma análise descritiva dos dados, a fim de se verificar o seu comportamento. A Tabela 1 apresenta os valores mínimos e máximos, assim como a média, o desvio padrão e o coeficiente de variação das variáveis utilizadas no estudo. 
Tabela 1 - Estatística descritiva dos dados das empresas da amostra

\begin{tabular}{lrrrrrrr}
\hline Variável & Observaçoses & \multicolumn{1}{l}{ Mínimo } & Máximo & Média & Desvio padrão & $\begin{array}{c}\text { Coeficiente de } \\
\text { Variação (\%) }\end{array}$ \\
\hline DCH & 224 & $0,42 \%$ & 1,00 & 0,83 & 0,14 & 17,06 \\
\hline TAM & 224 & $661.078,00$ & $1.300 .000 .000,00$ & $82.000 .000,00$ & $225.000 .000,00$ & 274,39 \\
\hline CAC & 224 & 0,05 & 1,00 & 0,41 & 0,21 & 52,32 \\
\hline GRI & 224 & 0,33 & 19,27 & 2,17 & 2,23 & 102,51 \\
\hline ROE & 224 & $-2,49$ & 0,73 & 0,10 & 0,28 & 279,86 \\
\hline END & 224 & 0,14 & 0,95 & 0,62 & 0,17 & 27,43 \\
\hline ECH & 224 & 0,03 & 4,69 & 0,32 & 0,38 & 119,20 \\
\hline FOn
\end{tabular}

Fonte: os autores.

Na Tabela 1, observa-se que o disclosure do capital humano (DCH) registra uma média de 0,83, representando, assim, uma alta evidenciação das questões propostas por Maçambanni et al. (2012). Em um contexto distinto e com métrica de disclosure diferente, Goh e Lim (2004) verificaram que as empresas malaias divulgam 53\% dos itens referentes ao capital humano; por sua vez, Whiting e Woodcock (2011), que utilizaram a mesma métrica de Goh e Lim (2004), observaram que apenas 22\% dos itens do capital humano foram divulgados pelas empresas australianas.

Quanto aos fatores determinantes do disclosure, percebe-se que, no geral, há uma alta dispersão dos dados, com base no desvio padrão e no coeficiente de variação, em especial para a variável tamanho (TAM), representada pelo Ativo Total, e para a rentabilidade (ROE).

Quanto à concentração acionária (CAC), representada pela proporção das ações pertencentes ao maior acionista, verifica-se uma média de 41\%, evidenciando uma alta concentração acionária nas empresas, comparativamente ao resultado encontrado no estudo de Whiting e Woodcock (2011), no qual analisaram a concentração acionária (CAC), representada pela proporção das ações de propriedade dos três maiores acionistas, e encontraram a média de 38,4\% nas empresas australianas.

Chen, Cheng e Hwang (2005) verificaram, no contexto taiwanês, que a rentabilidade (ROE) é baixa $(0,01)$ em comparação com a rentabilidade das empresas brasileiras investigadas neste estudo $(0,10)$. Dominguez (2011) constatou que as empresas espanholas apresentam um alto endividamento (END), assim como as empresas brasileiras.

As empresas da amostra apresentaram um grau de intangibilidade (GRI) médio de 2,17, portanto, acima do que foi encontrado na pesquisa de Maditinos et al. 
(2011) para as empresas gregas listadas na Athens Stock Exchange, que foi de 1,69. Quanto à eficiência do capital humano (ECH), Boscov e Bispo (2010) realizaram uma análise temporal de 1997 a 2006, e observaram que, em média, a ECH é de aproximadamente 0,2 , divergente do resultado encontrado neste estudo para o período entre 2010 e 2013, em que se verificou uma média de 0,32.

Depois de realizada a análise descritiva, procedeu-se ao teste de Correlação de Pearson, para se verificarem os primeiros indícios de relação entre o DCH e seus fatores determinantes (Tabela 2).

Tabela 2 - Resultados do Teste de Correlação de Pearson

\begin{tabular}{|c|c|c|c|c|c|c|c|c|c|c|c|c|}
\hline & DCH & TAM & & CAC & & GRI & & ROE & & END & & $\mathrm{ECH}$ \\
\hline DCH & 1,000 & & & & & & & & & & & \\
\hline TAM & 0,048 & 1,000 & & & & & & & & & & \\
\hline CAC & 0,048 & $-0,117$ & $\left({ }^{*}\right)$ & 1,000 & & & & & & & & \\
\hline GRI & $-0,092$ & $-0,196$ & $\left({ }^{* * *}\right)$ & $-0,144$ & $\left(^{* *}\right)$ & 1,000 & & & & & & \\
\hline ROE & 0,062 & 0,064 & & $-0,176$ & $\left({ }^{* * *}\right)$ & 0,247 & $\left({ }^{* * *}\right)$ & 1,000 & & & & \\
\hline END & 0,098 & 0,389 & $\left({ }^{* * *}\right)$ & 0,160 & $\left(^{* *}\right)$ & 0,052 & & $-0,138$ & $\left({ }^{* *}\right)$ & 1,000 & & \\
\hline ECH & $-0,008$ & $-0,129$ & $\left({ }^{*}\right)$ & 0,085 & & $-0,059$ & & $-0,417$ & $\left({ }^{* * *}\right)$ & 0,125 & $\left({ }^{*}\right)$ & 1,000 \\
\hline
\end{tabular}

Fonte: os autores.

Nota: (") Resultado significante a 10\%; $\left(^{* *}\right)$ resultado significante a $5 \%$; $\left(^{* * *}\right)$ resultado significante a $1 \%$.

Na Tabela 2, observa-se que nenhum dos fatores apresenta relação significativa com o DCH. Entretanto, os fatores determinantes evidenciaram algumas relações entre si. O tamanho (TAM) apresentou relação negativa e significante com a concentração acionária (CAC), com o grau de intangibilidade (GRI) e com a eficiência do capital humano (ECH), e relação positiva e significante com o endividamento (END). A concentração acionária, por sua vez, apresentou relação negativa e significante com o grau de intangibilidade (GRI) e com a rentabilidade (ROE). Já o grau de intangibilidade (GRI) mostrou uma relação positiva e significante com a rentabilidade (ROE). A rentabilidade (ROE) demonstrou relação negativa e significante com o endividamento (END) e com a eficiência do capital humano (ECH), enquanto o endividamento (END) apresentou relação positiva e significante com a eficiência do capital humano $(\mathrm{ECH})$. Ressalte-se que esse resultado é ainda preliminar, o qual pode ser verificado com a aplicação de outros testes, como, por exemplo, a Regressão Linear Múltipla com dados em painel, considerando o período em análise (2010-2013). Para tanto, foram realizados os testes para se verificarem os modelos de estimação (POLS, efeitos fixos e efeitos aleatórios) a serem utilizados. 
A Tabela 3 apresenta o resultado dos testes de Breusch-Pagan e de Hausman. Esses testes procuram verificar qual é o modelo de estimação da regressão, se o POLS, os efeitos aleatórios ou os efeitos fixos.

Tabela 3 - Testes de Breusch-Pagan e de Hausman

\begin{tabular}{|c|c|c|c|c|c|c|c|}
\hline TEST & DE BREI & SCH-PAGAN & TEST & DE HA & JSMAN & & \\
\hline & VAR & $\begin{array}{l}\text { SD = } \\
\text { SQRT(VAR) }\end{array}$ & & (B) & (B) & (B-B) & $\begin{array}{l}\text { SQRT(DIAG(V_B- } \\
\text { V_B)) }\end{array}$ \\
\hline DCH & 0,049 & 0,2214 & & $\mathrm{FE}$ & $\mathrm{RE}$ & DIFERENÇA & S.E. \\
\hline $\mathrm{E}$ & 0,0244 & 0,1563 & TAM & 0,195 & 0,004 & 0,191 & 0,07 \\
\hline $\mathrm{U}$ & 0,0255 & 0,1595 & CAC & $-0,112$ & $-0,04$ & $-0,073$ & 0,168 \\
\hline $\mathrm{QUI}^{2}$ & & 71,39 & GRI & $-0,003$ & $-0,012$ & 0,009 & 0,018 \\
\hline SIG. & & 0,00 & ROE & 0,078 & 0,108 & $-0,03$ & 0,044 \\
\hline & & & END & $-0,146$ & 0,168 & $-0,314$ & 0,269 \\
\hline & & & $\mathrm{ECH}$ & 0,064 & 0,051 & 0,014 & 0,013 \\
\hline & & & $\mathrm{QUI}^{2}$ & & & & 11,68 \\
\hline & & & SIG. & & & & 0,0695 \\
\hline
\end{tabular}

Fonte: os autores.

O resultado do teste de Breusch-Pagan mostrado na Tabela 3 ajuda na rejeição da hipótese nula de que há adequação do modelo POLS em relação ao modelo de efeitos aleatórios, já que o Qui² possui significância de até 5\%. Desse modo, o melhor modelo seria o de efeitos aleatórios. Esse resultado é confirmado por meio do teste de Hausman, em que é aceita a hipótese nula de que o modelo de efeitos aleatórios oferece estimativas dos parâmetros mais consistentes do que o modelo de efeitos fixos, haja vista que o Qui é superior à significância de 5\%. Desse modo, o modelo de estimação da Regressão Linear Múltipla com dados em painel é o de efeitos aleatórios, cujo resultado verifica-se na Tabela 4.

Tabela 4 - Fatores determinantes do disclosure do capital humano

\begin{tabular}{|c|c|c|c|}
\hline Variável & Coeficiente & \multicolumn{2}{|c|}{ Significância } \\
\hline Tamanho & 0,0039 & & 0,7960 \\
\hline Concentração Acionária & $-0,0398$ & & 0,7030 \\
\hline Grau de Intangibilidade & $-0,0121$ & * & 0,0780 \\
\hline Rentabilidade & 0,1079 & $* * *$ & 0,0060 \\
\hline Endividamento & 0,1680 & & 0,1970 \\
\hline Eficiência do Capital Humano & 0,0506 & * & 0,0840 \\
\hline Constante & 0,5539 & $* *$ & 0,0280 \\
\hline Número de empresas & & & 56 \\
\hline Número de observações & & & 224 \\
\hline Wald Qui ${ }^{2}$ & & & 14,09 \\
\hline Valor -p & & & $0,0256^{* *}$ \\
\hline $\mathrm{R}^{2}$ & & & \\
\hline
\end{tabular}

Fonte: os autores.

Nota. $\left({ }^{*}\right)$ Resultado significante a 10\%; $\left({ }^{* *}\right)$ resultado significante a 5\%; $\left(^{* * *}\right)$ resultado significante a $1 \%$. 
Com base no teste Wald Qui², que verifica a hipótese de que pelo menos um dos coeficientes de regressão dos preditores não é nulo, mostrou-se uma significância ao nível de 5\%. Desse modo, o modelo é válido, com um poder explicativo de aproximadamente 2,3\%, demonstrando que há outras variáveis capazes de influenciar o disclosure do capital humano.

Nota-se, na Tabela 4, que as variáveis grau de intangibilidade, rentabilidade e eficiência do capital humano apresentaram relação significativa com o disclosure do capital humano. Desse modo, são rejeitadas as hipóteses $\mathrm{H}_{1}, \mathrm{H}_{3}$ e $\mathrm{H}_{5}$, já que o tamanho, a concentração acionária e o endividamento não apresentaram relação significativa. Destaca-se, entretanto, que os resultados apontam indícios que corroboram a literatura (FELÍCIO; COUTO; CAIADO, 2014; FERREIRA, 2008; GUTHRIE; PETTY; RICCERI, 2006; MAÇAMBANNI et al., 2012; SÁENZ, 2005; WHITING; WOODCOCK, 2011), pois o tamanho apresentou relação positiva, podendo-se inferir que as empresas maiores divulgam mais informações sobre o capital humano; a concentração acionária demonstrou relação negativa, indicando que quanto maior é a concentração acionária, menor é a evidenciação do capital humano; e o endividamento mostrou relação positiva, sugerindo que as empresas mais endividadas fazem mais divulgação do capital humano.

O grau de intangibilidade demonstrou relação negativa com o disclosure do capital humano, rejeitando-se, assim, a hipótese $\mathrm{H}_{4}$, de que o grau de intangibilidade está relacionado positivamente com o disclosure do capital humano. Destarte, percebe-se um não alinhamento entre a intangibilidade da empresa e a divulgação dos seus recursos intangíveis, no caso, o capital humano. Isso pode ocorrer em razão do nível de importância que esses recursos têm na composição da intangibilidade da empresa: ou esses recursos têm baixa importância nas empresas ou não conseguem ser explicitados no grau de intangibilidade.

A rentabilidade apresentou relação positiva com o disclosure do capital humano, aceitando-se, assim, a hipótese $\mathrm{H}_{2}$, de que a rentabilidade está relacionada positivamente com o disclosure do capital humano. Desse modo, as empresas mais rentáveis mostram-se mais preocupadas com o capital humano. Akerlof (1970) e Meek et al. (1995) asseveram que essas empresas fazem isso na busca de diferenciação e redução de risco. Scharf, Fernandes e Pacheco (2014) também apontam que o capital humano é fundamental para a diferenciação das organizações, considerando-se a proposta de valor. Outro fator é apontado por Domench e Dallo (2001), segundo os quais os gestores estão propensos a evidenciar mais informações quando a empresa se encontra em situação favorável. 
A eficiência do capital humano mostrou relação positiva com o disclosure do capital humano, aceitando-se, assim, a hipótese $\mathrm{H}_{6}$, de que a eficiência do capital humano está relacionada positivamente com o disclosure do capital humano. Dessa forma, verifica-se o alinhamento entre a mensuração do capital humano e a sua divulgação. Esse resultado confirma o posicionamento de Bhasin e Shaikh (2011) de que o disclosure demonstra a política que a empresa adota para seus colaboradores, atraindo talentos e gerando benefícios futuros, sendo fruto da eficiência do capital humano.

Os resultados relacionados às empresas da amostra corroboram o estudo de Chen, Cheng e Hwang (2005), no qual o capital intelectual está relacionado positivamente com o desempenho financeiro (rentabilidade); o de Ferreira (2008), em que não se encontrou relação entre o capital intelectual e a concentração acionária e o endividamento; o de Clarke, Seng e Whiting (2011), que mostrou existir uma relação direta entre o capital intelectual e o desempenho das empresas australianas de capital aberto; o de Whiting e Woodcock (2011), segundo o qual a concentração acionária e o endividamento não influenciam o capital intelectual; o de Maçambanni et al. (2012), no qual se verificou que o nível de disclosure do capital intelectual possui associação com a rentabilidade das empresas; e o de Felício, Couto e Caiado (2014), em que se demonstrou que o desempenho organizacional é fortemente influenciado pelo capital humano.

Por sua vez, os resultados do estudo diferem dos achados de Sáenz (2005), já que estes demonstraram uma relação positiva entre o capital humano e o market-to-book; os de Guthrie, Petty e Ricceri (2006), pois o tamanho está relacionado positivamente com o nível de disclosure do capital intelectual; e os de Ferreira (2008), já que o resultado demonstrou relação positiva entre o disclosure do capital intelectual e o tamanho.

Destarte, no contexto brasileiro, percebe-se que os fatores que influenciam a divulgação do capital humano são a rentabilidade, mensurada por meio do ROE, e a eficiência do capital humano, dada pela razão entre o valor adicionado distribuído com empregados e o valor adicionado total. Os demais fatores analisados não influenciaram a divulgação do capital humano, como o tamanho, a concentração acionária e o endividamento, ou a influenciaram de forma inversa, como o grau de intangibilidade.

Frise-se, ainda, a importância do capital humano para as empresas que, com base na Visão Baseada em Recursos, consideram-no um recurso estratégico necessário para obter vantagem competitiva e, assim, criar valor para os acionistas. Entre as categorias de capital intelectual, o capital humano possui a particularidade de pertencer à organização somente enquanto ela dispõe de determinados colaboradores em seu quadro. Esse recurso é perdido no momento em que tais colaboradores deixam a organização. Desse modo, cabe à gestão investir em capital humano, a fim de construir e 
reter talentos. Nesse contexto, a divulgação do capital humano demonstra a estratégia e a importância que as empresas atribuem aos seus colaboradores, tornando-se, também, uma forma de atração de novos talentos.

\section{CONCLUSÃO}

No presente estudo se investigaram os fatores determinantes do disclosure do capital humano pelas empresas brasileiras listadas na BM\&FBovespa, considerando a Visão Baseada em Recursos como seu pressuposto teórico. Fez-se uso da Regressão Linear Múltipla com dados em painel, em uma amostra que reuniu 56 empresas que divulgaram relatórios anuais e/ou de sustentabilidade referentes aos exercícios de 2010, 2011, 2012 e 2013, totalizando 224 observações.

Os primeiros resultados foram obtidos por meio da estatística descritiva e do teste de Correlação de Pearson. Na estatística descritiva, observou-se que as empresas da amostra praticam alto disclosure do capital humano (DCH), comparativamente a estudos estrangeiros anteriores, em razão da métrica adotada para o DCH ou do contexto cultural dos países. Verificou-se, ainda, que a amostra apresenta: uma alta concentração acionária, sendo essa uma característica da realidade brasileira, conforme apontam La Porta et al. (1998); uma rentabilidade em torno de 10\%; um alto endividamento, de aproximadamente 62\%; um grau de intangibilidade expressivo, em que o valor de mercado da empresa é aproximadamente duas vezes maior que o seu patrimônio líquido; e uma eficiência do capital humano de aproximadamente 32\%. O principal resultado observado no teste de Correlação de Pearson foi que os fatores determinantes, individualmente, não possuem relação significativa com o DCH, entretanto, os fatores entre si possuem certas relações significativas, sendo o tamanho o fator que apresenta maior relação com os demais.

Por sua vez, os resultados da regressão revelaram que a rentabilidade e a eficiência do capital humano estão relacionadas positivamente com o DCH, confirmando os preceitos da literatura. O grau de intangibilidade apresentou relação inversa com o DCH, enquanto o tamanho, a concentração acionária e o endividamento não apresentaram relação significante. Logo, as empresas mais rentáveis e com maior eficiência do capital humano divulgam mais informações sobre o capital humano, confirmando-se, assim, as hipóteses $\mathrm{H}_{2}$ e $\mathrm{H}_{6}$.

A Visão Baseada em Recursos reconhece o capital humano como um recurso estratégico raro, imitável e valoroso, considerado um dos primordiais recursos que as empresas devem gerenciar, em razão da sua capacidade de obter vantagem competitiva. Desse modo, observou-se que, no geral, as empresas brasileiras da amostra estão preocupadas com a evidenciação desse recurso estratégico em seus relatórios, apesar 
de ele não ser mensurado e reconhecido pela contabilidade. Cabe à gestão desenvolver estratégias que evidenciem a importância dos colaboradores, assim como políticas de investimento na criação e retenção de talentos. No Brasil, uma forma de destaque das empresas que se preocupam com seus colaboradores é a inclusão no ranking As melhores empresas para você trabalhar, da revista Você S/A, que demonstra a reputação das empresas nesse contexto.

Ressalte-se que o presente estudo tem relevância no cenário acadêmico e no âmbito empresarial, pois poucas são as obras que verificam os fatores que influenciam o disclosure do capital humano, além de o capital humano ser um recurso importante nas organizações.

Constituem limitações desta pesquisa, entre outras, a métrica das variáveis utilizadas, a população constituída somente por empresas listadas na BM\&FBovespa que publicaram o relatório anual e/ou de sustentabilidade, conforme já mencionado, além do curto período de análise. Assim, para futuras pesquisas, sugere-se a ampliação do universo das empresas componentes da base amostral, utilizando-se documentos obrigatórios, como o relatório de administração, assim como a ampliação do intervalo temporal de investigação. Além disso, sugere-se a utilização de uma métrica que avalie as características qualitativas e quantitativas do capital humano. Por fim, recomenda-se, ainda, a análise em diferentes contextos culturais, para, assim, verificar-se a influência da cultura do país ou mesmo a cultura da empresa no disclosure do capital humano.

\section{REFERÊNCIAS}

ABEYSEKERA, I.; GUTHRIE, J. Human capital reporting in a developing nation. British Accounting Review, v. 36, p. 251-268, 2004.

AKERLOF, G. A. The market for "lemons": quality uncertainty and the market mechanism. The Quarterly Journal of Economics, v. 84, p. 488-500, 1970.

ALBERS, C.; GÜNTHER, T. Disclose or not disclose: determinants of social reporting for Stoxx Europe 600 firms. Zeitschrift Fur Planung Und Unternehmenssteuerung, v. 21, p. 323-347, 2010.

APRIL, K. A.; BOSMA, P.; DEGLON, D. A. IC measurement and reporting: establishing a practice in SA mining. Journal of Intellectual Capital, v. 4, p. 165-180, 2003. 
AX, C.; MARTON, J. Human capital disclosures and management practices. Journal of Intellectual Capital, v. 9, p. 433-455, 2008.

BARDIN, L. Análise de conteúdo. Lisboa: Edições 70, 2009.

BARNEY, J. Firm resources and sustained competitive advantage. Journal of Management, v. 17, p. 99-120, 1991.

BEATTIE, V. The future of corporate reporting: a review article. Irish Accounting Review, v. 7, p. 1-36, 2000.

BEUREN, I. M.; HEIN, N.; BOFF, M. L. Estratégias de legitimidade organizacional de Lindblom versus geração familiar gestora de empresas familiares. Revista Iberoamericana de Contabilidad e Géstion, v. 9, n. 17, p. 1-20, 2011.

BHASIN, M.; SHAIKH, J. M. Intellectual capital disclosures in the annual reports: a comparative study of the Indian and Australian IT-corporations. International Journal of Managerial and Financial Accounting, v. 3, i. 4, p. 379-402, 2011.

BINDER, M. P. Rede de recurso: um modelo desenvolvido a partir do caso Gol Linhas Aéreas. Revista de Administração e Inovação - RAI, v. 6, n. 2, p. 28-43, 2009.

BONTIS, N. Intellectual capital disclosure in Canadian corporations. Journal of Human Resource Costing \& Accounting, v. 7, p. 9-20, 2003.

BONTIS, N. Managing organisational knowledge by diagnosing intellectual capital: framing and advancing the state of the field. International Journal of Technology Management, v. 18, p. 433-462, 1999.

BOSCOV, C.; BISPO, J. S. A comparação da distribuição da riqueza gerada entre os setores de serviço, comércio e indústria. ConTexto, v. 10, n. 17, p. 59-70, 2010.

BOUDREAU, J. W.; RAMSTAD, P. M. Measuring intellectual capital: learning from financial history. Human Resource Management, v. 36, p. 343-356, 1997.

BOZZOLAN, S.; FAVOTTO, F.; RICCERI, F. Italian annual intellectual capital disclosure: an empirical analysis. Journal of Intellectual Capital, v. 4, p. 543-558, 2003. 
BRITO, L. A. L.; VASCONCELOS, F. C. A heterogeneidade do desempenho, suas causas e o conceito de vantagem competitiva: proposta de uma métrica. Revista de Administração Contemporânea, v. 8, p. 107-129, 2004.

BROOKING, A. Intellectual capital: core assets for the third millennium enterprise. Londres: International Thomson Business Press, 1997.

CARVALHO, A.; SOUZA, L. Ativos intangíveis ou capital intelectual: discussões das contradições na literatura e propostas para sua avaliação. Perspectivas em Ciência da Informação, v. 4, p. 73-83, 1999.

CHEN, M.-C.; CHENG, S.-J.; HWANG, Y. An empirical investigation of the relationship between intellectual capital and firms' market value and financial performance. Journal of Intellectual Capital, v. 6, p. 159-176, 2005.

CLARKE, M.; SENG, D.; WHITING, R. H. Intellectual capital and firm performance in Australia. Journal of Intellectual Capital, v. 12, p. 505-530, 2011.

COLLIS, J.; HUSSEY, R. Pesquisa em administração: um guia prático para os alunos de graduação e pós-graduação. 2. ed. Porto Alegre: Bookman, 2005.

CUNHA, J. V. A.; RIBEIRO, M. D. S.; SANTOS, A. A demonstração do valor adicionado como instrumento de mensuração da distribuição da riqueza. Revista Contabilidade \& Finanças, v. 16, p. 7-23, 2005.

DOMENCH, P. A.; DALLO, F. L. Algunos determinantes de la información medioambiental divulgada por las empresas españolas cotizadas. Revista de Contabilidad, v. 4, n. 1, p. 129-153, 2001.

DOMINGUEZ, A. A. The impact of human resource disclosure on corporate image. Journal of Human Resource Costing \& Accounting, v. 15, p. 279-298, 2011.

ECCLES, R.; MAVRINAC, S. Improving the corporate disclosure process. Sloan Management Review, v. 4, p. 11-25, 1995.

EDVINSSON, L.; MALONE, M. S. Intellectual capital: realizing your company’s true value by finding its hidden brainpower. New York: Harper Business, 1997.

FELÍCIO, J. A.; COUTO, E.; CAIADO, J. Human capital, social capital and organizational performance. Management Decision, v. 52, p. 350-364, 2014. 
FERREIRA, A. L. P. A divulgação de informação sobre capital intelectual em Portugal: uma análise exploratória. 2008. 91 p. Tese (Mestrado em Contabilidade)Universidade do Porto, Porto, Portugal, 2008.

GOH, P. C.; LIM, K. P. Disclosing intellectual capital in company annual reports: evidence from Malaysia. Journal of Intellectual Capital, v. 5, p. 500-510, 2004.

GRANT, R. M. The resource-based theory of competitive advantage: implications for strategy formulation. California Management Review, v. 33, i. 13, p. 114-135, 1991.

GUTHRIE, J.; PETTY, R.; RICCERI, F. The voluntary reporting of intellectual capital: comparing evidence from Hong Kong and Australia. Journal of Intellectual Capital, v. 7, p. 254-271, 2006.

HOLLAND, L.; FOO, Y. B. Differences in environmental reporting practices in the UK and the US: the legal and regulatory context. British Accounting Review, v. 35, p. 1-18, 2003.

HOSSAIN, M. The extent of disclosure in annual reports of banking companies: the case of India. European Journal of Scientific Research, v. 23, i. 4, p. 659-680, 2008.

LA PORTA, R. et al. Law and finance. Journal of Political Economy, v. 106, i. 6, p. 1113-1155, 1998.

LANZANA, A. P. Relação entre disclosure e governança corporativa das empresas brasileiras. 2004. 154 p. Dissertação (Mestrado em Administração)-Universidade de São Paulo, São Paulo, 2004.

MAÇAMBANNI, M. V. et al. Relação entre o nível de disclosure do capital intelectual e características das companhias listadas no índice BM\&FBovespa. Revista Alcance, v. 19, n. 3, 345-361, 2012.

MADITINOS, D. et al. The impact of intellectual capital on firms' market value and financial performance. Journal of Intellectual Capital, v. 12, p. 132-151, 2012.

MAINES, L. A. et al. Recommendations on disclosure of nonfinancial performance measures. Accounting Horizons, v. 16, i. 4, p. 353-362, 2002. 
MARTINS, G. A.; THEÓPHILO, C. N. Metodologia da investigação científica para ciências sociais aplicadas. São Paulo: Atlas, 2009.

MEEK, G. K.; ROBERTS, C. B.; GRAY, S. J. Factors influencing voluntary annual report disclosures by U.S., U.K. and continental European multinational corporations. Journal of International Business Studies, v. 26, i. 3, p. 555-572, 1995.

MOURITSEN, J.; LARSEN, H. T.; BUKH, P. N. Dealing with the knowledge economy: intellectual capital versus balanced scorecard. Journal of Intellectual Capital, v. 6, p. 8-27, 2005.

OLIVEIRA, L.; RODRIGUES, L. L.; CRAIG, R. Intellectual capital reporting in sustainability reports. Journal of Intellectual Capital, v. 11, p. 575-594, 2010.

OLSSON, B. Measuring personnel through human resources accounting reports: a procedure for management of learning. The hospital sector in northwest Stockholm. Journal of Human Resource Costing \& Accounting, v. 4, i. 1, p. 49-56, 1999.

ORGANISATION FOR ECONOMIC CO-OPERATION AND DEVELOPMENT. Measuring and reporting intellectual capital: experience, issues, and prospects. 1999.

PAIVA, R. V. C.; BARBOSA, F. V.; GONÇALVES, R. G. A visão baseada em recursos: o que se vê é diferente, mas é igual. Reuna, v. 13, n. 3, p. 27-39, 2008.

PETTY, R.; GUTHRIE, J. Intellectual capital literature review: measurement, reporting and management. Journal of Intellectual Capital, v. 1, p. 155-176, 2000.

PIACENTINI, N. Evidenciação contábil voluntária: uma análise da prática adotada por companhias abertas brasileiras. 2004. 132 p. Dissertação (Mestrado em Ciências Contábeis)- Universidade do Vale do Rio dos Sinos, São Leopoldo, 2004.

PULIC, A. Intellectual capital - does it create or destroy value? Measuring Business Excellence, v. 8, i. 1, p. 62-68, 2004.

PULIC, A. Measuring the performance of intellectual potential in the knowledge economy. In: WORLD CONGRESS ON THE MANAGEMENT AND MANAGING OF INTELLECTUAL CAPITAL, 2., 1998, Hamilton. Anais... Hamilton, 1998.

RAFFOURNIER, B. The determinants of voluntary financial disclosure by Swiss listed companies. European Accounting Review, v. 4, i. 2, p. 261-280, 1995. 
REVERTE, C. Determinants of corporate social responsibility disclosure ratings by Spanish listed firms. Journal of Business Ethics, v. 88, p. 351-366, 2009.

RIAHI-BELKAOUI, A. Intellectual capital and firm performance of US multinational firms: a study of the resource-based and stakeholder views. Journal of Intellectual Capital, v. 4, i. 2, p. 215-226, 2003.

ROOS, J. Exploring the concept of intellectual capital (IC). Long Range Planning, v. 31, i. 1, p. 150-153, 1998.

SACKMAN, S.; FLAMHOLTZ, E.; BULLEN, M. Human resource accounting: a state of art review. Journal of Accounting Literature, v. 8, p. 235-264, 1989.

SÁENZ, J. Human capital indicators, business performance and market-to-book ratio. Journal of Intellectual Capital, v. 6, p. 374-384, 2005.

SAMPIERI, R. H.; COLLADO, C. F.; LÚCIO, P. B. Metodologia de pesquisa. 3. ed. São Paulo: McGraw Hill, 2013.

SCHARF, E. R.; FERNANDES, J.; PACHECO, R. C. D. S. O capital humano como um driver das estratégias de marketing em empresas inovadoras: o caso da Apple.

RACE: Revista de Administração, Contabilidade e Economia, v. 13, n. 2, p. 425452, 2014.

SHIH, K. H.; CHANG, C. J.; LIN, B. Assessing knowledge creation and intellectual capital in banking industry. Journal of Intellectual Capital, v. 11, i. 1, p. 74-89, 2010.

SINGH, S.; KANSAL, M. Voluntary disclosures of intellectual capital: an empirical analysis. Journal of Intellectual Capital, v. 12, p. 301-318, 2011.

SONNIER, B. M. Intellectual capital disclosure: high-tech versus traditional sector companies. Journal of Intellectual Capital, v. 9, p. 705-722, 2008.

STEWART, T. A. Intellectual capital: the new wealth of organizations. New York: Doubleday/Currency, 1997.

SVEIBY, K. E. Intellectual capital: thinking ahead. Australian CPA, v. 68, i. 5, p. 18-22, 1998. 
SVEIBY, K. E. The new organizational wealth: managing and measuring knowledge-based assets. San Francisco: Berrett-Koehler, 1997.

TOLFO, S. D. R.; PICCININI, V. C. As melhores empresas para trabalhar no Brasil e a qualidade de vida no trabalho: disjunções entre a teoria e a prática. Revista de Administração Contemporânea, v. 5, p. 165-193, 2001.

TONDOLO, V. A. G.; BITENCOURT, C. C. Uma perspectiva baseada em recursos no agronegócio cooperativo. RAE Eletrônica, v. 7, n. 1, 2008.

VERGAUWEN, P. G. M. C.; ALEM, F. J. C. V. Annual report IC disclosures in the Netherlands, France and Germany. Journal of Intellectual Capital, v. 6, p. 89-104, 2005.

WHITE, G.; LEE, A.; TOWER, G. Drivers of voluntary intellectual capital disclosure in listed biotechnology companies. Journal of Intellectual Capital, v. 8, p. 517-537, 2007.

WHITING, R. H.; WOODCOCK, J. Firm characteristics and intellectual capital disclosure by Australian companies. Journal of Human Resource Costing \& Accounting, v. 15, p. 102-126, 2011.

YI, A.; DAVEY, H. Intellectual capital disclosure in Chinese (mainland) companies. Journal of Intellectual Capital, v. 11, p. 326-347, 2010.

Como citar este artigo:

\section{ABNT}

GOIS, Alan Diógenes; LUCA, Marcia Martins Mendes de; MONTE JUNIOR, José Airton Alcantara. Fatores determinantes do Disclosure no capital humano. RACE: Revista de Administração, Contabilidade e Economia, Joaçaba: Ed. Unoesc, v. 15, n. 1, p. 201-226, jan./abr. 2016. Disponível em: <http://editora.unoesc.edu.br/index. php/race>. Acesso em: dia/mês/ano.

\footnotetext{
APA

Gois, A. D.; Luca, M. M. M. de.; Monte Jr., J. A. A. (2016). O impacto da crise financeira internacional sobre os investimentos públicos municipais. Efeitos do uso da informação “Edição limitada sobre percepções de preço e intenção de compra de produtos. RACE: Revista de Administração, Contabilidade e Economia, 15(1), 201226. Recuperado em dia/mês/ano, de http://editora.unoesc.edu.br/index.php/race
} 